\title{
ANALISIS FAKTOR-FAKTOR YANG MEMENGARUHI PELANGGARAN ATURAN BATAS KECEPATAN PADA RUAS JALAN PERKOTAAN
}

\author{
Jeremy Putra Jaya, David Christ Fernaldy Chandra, Rudy Setiawan, David \\ Wiyono \\ Teknik Sipil Universitas Kristen Petra \\ Email: m21416140@john.petra.ac.id,m21416165@john.petra.ac.id,rudy@ petra.ac.id, \\ davidwiy1412@petra.ac.id.
}

\begin{abstract}
Abstrak
Pelanggaran aturan batas kecepatan pada ruas jalan Kota Surabaya masih sering terjadi. Penelitian ini dilakukan untuk mengetahui sejauh mana responden memahami keberadaan kamera ETLE dan batas kecepatan di ruas jalan, serta faktor-faktor yang dapat memengaruhi pelanggaran batas kecepatan. Faktorfaktor yang digunakan dalam penelitian ini berbentuk 17 variabel. Penyebaran kuesioner dilakukan secara online dan didapatkan 117 responden. Sampel responden yang dibutuhkan untuk melakukan penelitian ini ditentukan dari hasil perhitungan uji slovin. Hasil dari jawaban responden diolah menggunakan SPSS, dan dilakukan beberapa uji seperti, uji validitas dan reliabilitas, dan dilakukan Categorical Principal Components Analysis. Hasil dari penelitian ini menunjukan jika jumlah responden yang mengetahui dan memahami tentang ETLE, jenis pelanggaran ETLE, dan batas kecepatan jalan perkotaan di Surabaya masih setara dengan jumlah responden yang ragu-ragu dan tidak mengetahui maupun memahami hal-hal tersebut. Dan dari indikator, ke-17 variabel tersebut telah tereduksi dan terbagi menjadi 2 dimensi.
\end{abstract}

Kata Kunci: Batas Kecepatan, Mengebut, Pelanggaran Lalu Lintas.

\section{Abstract}

Violation of speed limit rules on roads in the city of Surabaya is still common. This study was conducted to determine the extent to which respondents understand the presence of ETLE cameras and speed limits on roads, as well as factors that can affect speed limit violations. The factors used in this study are in the form of 17 variables. The questionnaire was distributed online and obtained by 117 respondents. The sample of respondents needed to conduct this research is determined from the results of the slovin test calculation. The results of the respondents' answers were processed using SPSS, and several tests were carried out such as validity and reliability tests, and Categorical Principal Components Analysis was carried out. The results of this study indicate that the number of respondents who know and understand about ETLE, types of ETLE violations, and urban road speed limits in Surabaya is still equivalent to the number of respondents who are hesitant and do not know or understand these things. And from the indicators, the 17 variables have been reduced and divided into 2 dimensions.

Copyright holder: Jeremy Putra Jaya, David Christ Fernaldy Chandra, Rudy Setiawan, David Wiyono (2022)

DOI : https://doi.org/10.54543/fusion.v2i02.147

Published by

: Rifa Institute 
Jeremy Putra Jaya, David Christ Fernaldy Chandra, Rudy Setiawan, David Wiyono

Keywords: Speed Limit, Speeding, Traffic Violation.

Diserahkan: 03-01-2022Ｄiterima: 25-01-2022Ｄiterbitkan: 20-02-2022

\section{Pendahuluan}

Surabaya sebagai kota terbesar kedua di Indonesia, memiliki pengguna kendaraan bermotor yang tinggi, sehingga tingkat pelanggaran lalu lintas dan tingkat kecelakaan lalu lintas menjadi tinggi. Menurut data Ditlantas Polda Jatim sebanyak 3.755 orang meninggal dunia akibat kecelakaan lalu lintas (laka lantas) di Jawa Timur sepanjang tahun 2020 (Wijayanto, 2021).

Salah satu pelanggaran lalu lintas tersebut adalah speeding atau mengemudi dengan kecepatan tinggi. Dalam upaya menertibkan pelanggar lalu lintas, Pemerintah Kota Surabaya bekerja sama dengan Dinas Perhubungan Surabaya dan Satuan Lalu Lintas Polrestabes Surabaya menerapkan Operasi penertiban Sistem ETLE (Electronic Traffic Law Enforcement) yang merupakan implementasi teknologi informasi untuk mengawasi dan menindak pelanggar lalu lintas secara elektronik (pengawasan melalui kamera CCTV), lalu menindak pelanggar dengan sistem.

Akan Tetapi, sebagian penduduk Kota Surabaya masih ada yang belum mengerti tentang ETLE beserta sanksinya, dan ada juga ada yang mengerti tetapi masih melanggar peraturan lalu lintas dan melakukan speeding. Sehingga, untuk mendapatkan hasil yang akurat diperlukan penelitian terhadap pengguna jalan (pengendara mobil dan motor) yang nantinya akan menjadi sarana edukasi dan sarana informasi pada pihak yang berwenang maupun masyarakat sehingga tertib berlalu lintas dapat lebih diterapkan di Kota Surabaya.

\section{Tinjauan Pustaka}

Menurut Peraturan Pemerintah No.34 Tahun 2006 Pasal 1 Ayat 3 tentang Jalan, jalan adalah prasarana transportasi darat yang meliputi segala bagian jalan, termasuk bangunan pelengkap dan perlengkapannya yang diperuntukkan bagi lalu lintas, yang berada pada permukaan tanah, di atas permukaan tanah, di bawah permukaan tanah dan/atau air, serta di atas permukaan air, kecuali jalan kereta api, jalan lori, dan jalan kabel.

Jalan perkotaan adalah jalan yang berada di dekat pusat perkotaan dengan jumlah penduduk lebih dari 100.000 jiwa. Daerah perkotaan dengan jumlah penduduk kurang dari 100.000 jiwa juga dapat digolongkan pada kelompok ini jika perkembangan jalan tersebut bersifat permanen dan terus menerus.

Menurut Ajun Komisaris Polisi Warih Hutomo selaku Kanit Turjawali Satlantas Polrestabes Surabaya yang di muat di Suara Surabaya, Batas kecepatan berkendara di jalan-jalan Kota Surabaya adalah $40 \mathrm{~km} / \mathrm{jam}$ namun peraturan ini tidak berlaku bagi kendaraan prioritas seperti ambulans dan pemadam kebakaran.

ETLE adalah suatu sistem teknologi informasi baru yang digunakan oleh kepolisian untuk meningkatkan pengawasan dan penindakan terhadap pelanggar lalu lintas yang 
berguna untuk meningkatkan kualitas berkendara, menurunkan tingkat fatalitas korban kecelakaan, mewujudkan dan memelihara keamanan, keselamatan, ketertiban dan kelancaran dalam berlalu lintas (Polda Jatim, 2021).

Speeding adalah perilaku dari pengemudi dimana pengemudi mengendarai kendaraannya melebihi batas kecepatan yang berlaku sesuai dengan peraturan yang ada. Speeding merupakan masalah keselamatan lalu lintas yang serius. Speeding juga menjadi penyebab tingginya tingkat kecelakaan yang terjadi. Hal ini dikarenakan semakin tinggi kecepatan sebuah kendaraan, maka semakin besar jarak yang dibutuhkan suatu kendaraan untuk berhenti dan tentunya resiko kecelakaan lalu lintas akan semakin meningkat (Kusuma et al., 2019). Ada beberapa faktor yang memengaruhi seseorang yang melakukan speeding diantaranya faktor dari dalam diri pengemudi seperti usia, jenis kelamin, tingkat alkohol dalam tubuh, pemahaman terhadap peraturan lalu lintas, terburuburu, dan lain-lain (Alonso et al., 2013). Lalu ada faktor dari jalan dan kendaraan seperti layout dari jalan, kualitas permukaan jalan, tenaga dari kendaraan, batas kecepatan maksimum. (Kusuma et al., 2019)

\section{Metode Penelitian}

Beberapa tahapan yang dibutuhkan adalah mempelajari referensi tentang speeding dan Sistem ETLE, studi literatur yang didapatkan dari jurnal, buku, majalah, koran, maupun skripsi baik dari media online maupun media cetak di mana beberapa data dan informasi yang dapat diolah menjadi bahan untuk membuat kuesioner dan untuk mencapai tujuan penelitian. Mengumpulkan data-data secara online melalui Google Form kepada pengemudi sepeda motor dan mobil yang diukur menggunakan Skala Likert menurut (Sugiyono, 2017) yaitu skala yang digunakan untuk mengukur sikap, pendapat, dan persepsi seseorang atau sekelompok orang tentang fenomena sosial. Skala Likert yang digunakan yaitu skala 1-5 di mana $1=$ Tidak Setuju, 2= Kurang Setuju, 3= Netral, 4= Cenderung Setuju, 5= Setuju.

Analisa data yang digunakan yaitu dengan menentukan sampel, membagikan kuesioner dan melakukan beberapa observasi lalu data-data tersebut disusun dan diolah melalui pengujian outlier, uji validitas dan uji reabilitas, analisis deskriptif, dan analisis data menggunakan Categorical Principal Components Analysis (CATPCA). Dari langkah-langkah dan pengolahan data tersebut akan didapatkan data-data yang akan dirangkum menjadi kesimpulan yang menjawab permasalahan yang ada.

\section{Hasil Dan Pembahasan}

Berdasarkan data yang diperoleh dari Badan Pusat Statistik penduduk kota Surabaya, jumlah penduduk yang berumur di atas 15 di Kota Surabaya, Agustus 2018 menunjukkan jumlah populasi sebesar 2.269.293 juta jiwa. Berdasarkan rumus Slovin, maka jumlah minimal sampel yang ditentukan sebanyak 101 responden.

Tabel 1. Tabel Uji Outlier 


\begin{tabular}{lrr}
\hline No. Responden & MAH_1 & PROB_MAH_1 \\
\hline 78 & 61,16758 & .0000 \\
\hline 31 & 50,33281 & .0008
\end{tabular}

Berdasarkan Pengujian outlier Mahalanobis yang dilakukan telah ditemukan dua orang dengan data yang tidak valid sehingga kedua orang tersebut dikeluarkan dari data responden. Sehingga terdapat 117 responden dengan data yang valid. Di bawah ini merupakan gambar diagram persentase dari data yang diperoleh. Mayoritas responden dari penelitian ini sudah memiliki pemahaman mengenai ETLE, jenis pelanggaran ETLE, dan batas kecepatan jalan perkotaan di Surabaya.

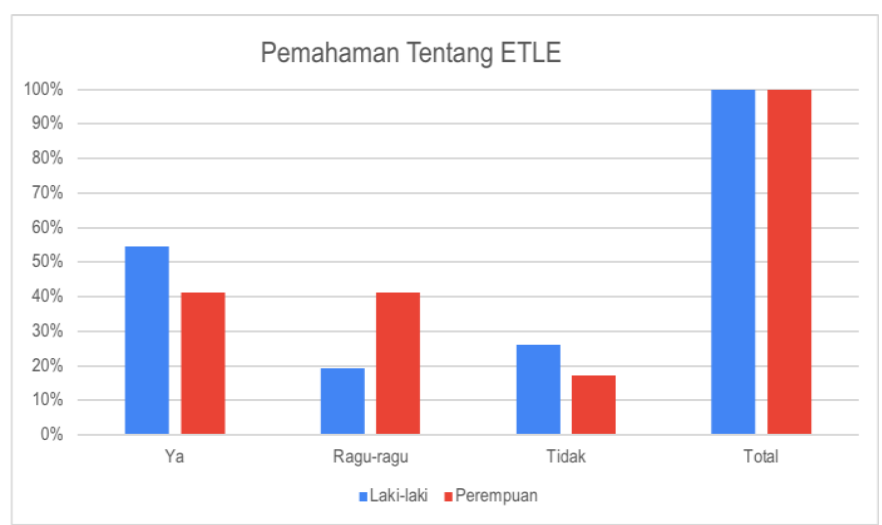

\section{Gambar 1. Pemahaman ETLE Menurut Gender}

Berdasarkan gambar 1, Laki-laki (55\%) yang paham tentang ETLE lebih banyak dibandingkan perempuan (41\%). Untuk yang ragu-ragu perempuan $(41 \%)$ lebih banyak daripada laki-laki (19\%). Sedangkan tidak paham tentang ETLE, laki-laki (26\%) lebih banyak daripada perempuan (17\%).

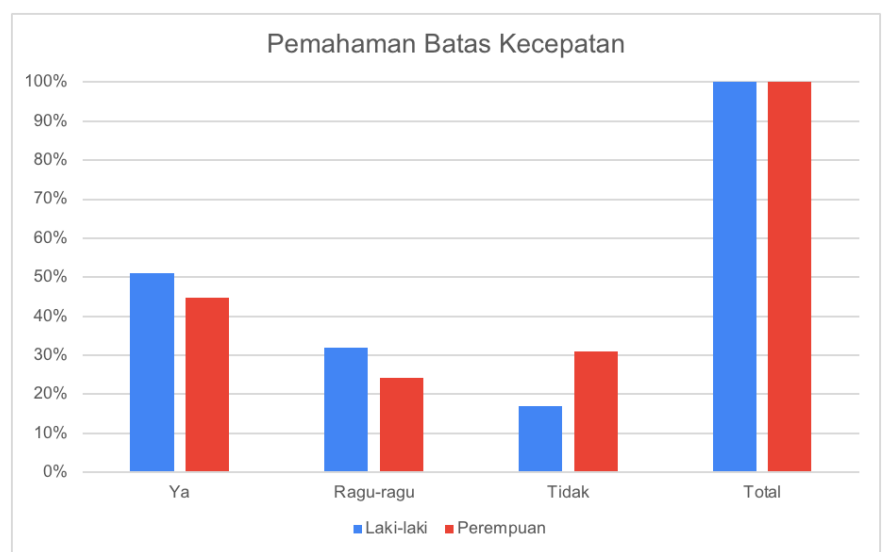

Gambar 2. Pemahaman Batas Kecepatan Menurut Gender

Berdasarkan gambar 2, Laki-laki (51\%) yang paham tentang batas kecepatan lebih banyak dibandingkan perempuan (45\%). Untuk yang ragu-ragu terhadap pemahaman batas kecepatan laki-laki (32\%) lebih banyak daripada perempuan (24\%). Sedangkan tidak paham tentang batas kecepatan, perempuan (17\%) lebih banyak daripada laki-laki $(31 \%)$. 


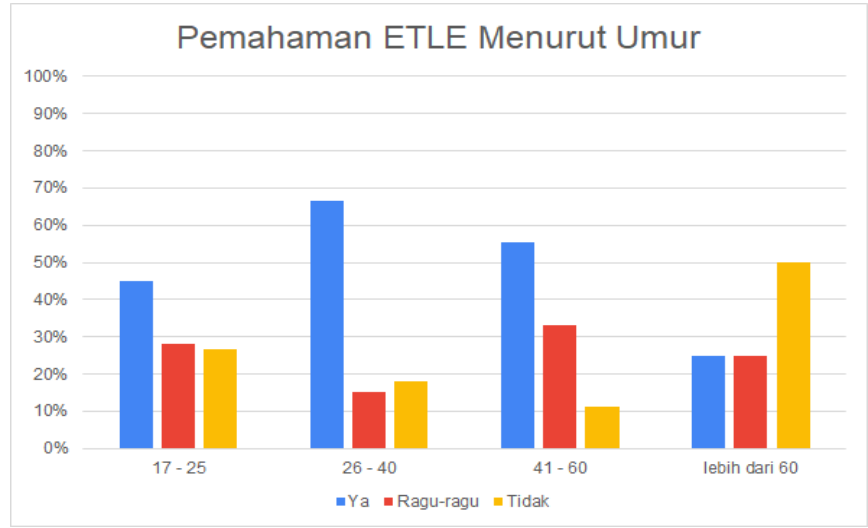

Gambar 3. Pemahaman Tentang Pelanggaran ETLE Menurut Umur

Berdasarkan Gambar 3, dapat dilihat bahwa persentase setiap rentang umur yang memiliki pemahaman tentang pelanggaran ETLE yang cukup tinggi kecuali pada rentang umur 17-25 dan lebih dari 60.

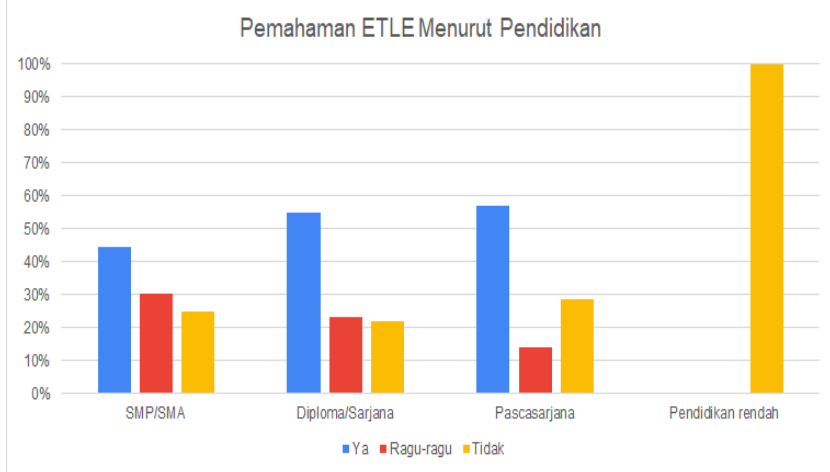

\section{Gambar 4. Gambar Pemahaman ETLE Menurut Pendidikan}

Berdasarkan gambar 4, dapat dilihat bahwa persentase setiap rentang pendidikan yang memiliki pemahaman tentang pelanggaran ETLE yang cukup tinggi kecuali pada rentang pendidikan SMP/SMA dan pendidikan rendah.

Pemahaman ETLE Menurut Pekerjaan

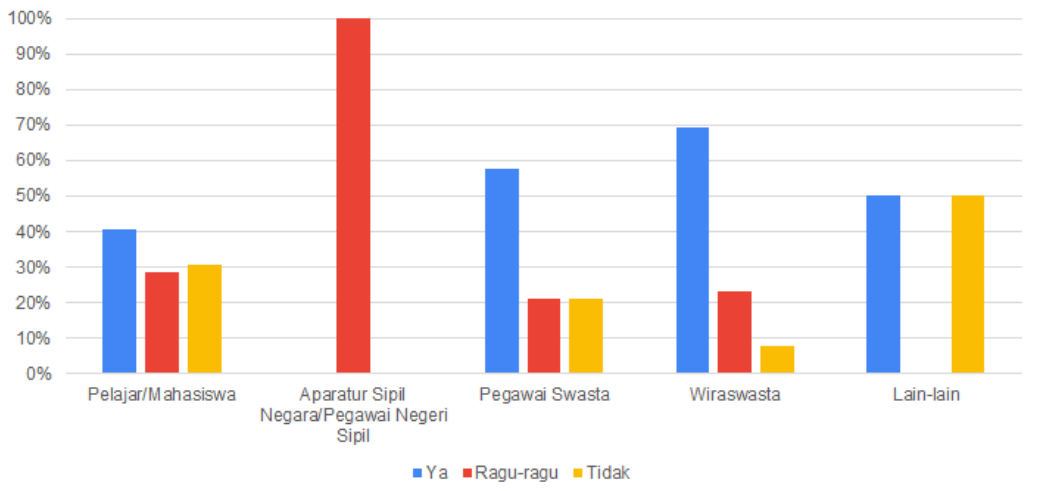

Gambar 5. Gambar Pemahaman ETLE Menurut Pekerjaan

Berdasarkan gambar 5, dapat dilihat bahwa persentase setiap pekerjaan yang memiliki pemahaman tentang pelanggaran ETLE yang cukup tinggi kecuali pada pekerjaan Pelajar/Mahasiswa. 
Jeremy Putra Jaya, David Christ Fernaldy Chandra, Rudy Setiawan, David Wiyono

Data-data pada gambar-gambar di atas akan diolah lebih lanjut melalui uji validitas dan uji reliabilitas, dan analisa CAPTCA.

Tabel 2. Tabel Uji Validitas

\begin{tabular}{|c|c|c|c|c|c|}
\hline \multicolumn{6}{|c|}{ Item-Total Statistics } \\
\hline & $\begin{array}{c}\text { Scale Mean } \\
\text { if Item } \\
\text { Deleted }\end{array}$ & $\begin{array}{c}\text { Scale } \\
\text { Variance } \\
\text { if Item } \\
\text { Deleted }\end{array}$ & $\begin{array}{l}\text { Corrected } \\
\text { Item-Total } \\
\text { Correlation }\end{array}$ & $\begin{array}{c}\text { Squared } \\
\text { Multiple } \\
\text { Correlation }\end{array}$ & $\begin{array}{l}\text { Cronbach's } \\
\text { Alpha if } \\
\text { Item } \\
\text { Deleted }\end{array}$ \\
\hline PBC & 68.47 & 190.044 & -0.205 & 0.365 & 0.866 \\
\hline Kondisi Ruas Jalan & 68.34 & 181.486 & 0.071 & 0.223 & 0.854 \\
\hline & 68.65 & 181.161 & 0.032 & 0.363 & 0.859 \\
\hline ATTITUDE & 69.20 & 158.418 & 0.704 & 0.739 & 0.831 \\
\hline ATTITUDE & 69.75 & 162.240 & 0.689 & 0.723 & 0.833 \\
\hline $\mathrm{PA}$ & 69.71 & 167.432 & 0.511 & 0.447 & 0.840 \\
\hline Punishment Avo & 68.42 & 171.625 & 0.331 & 0.512 & 0.847 \\
\hline Belief & 69.00 & 160.155 & 0.644 & 0.645 & 0.834 \\
\hline PA & 68.06 & 178.919 & 0.137 & 0.503 & 0.853 \\
\hline Belief & 69.69 & 164.887 & 0.628 & 0.681 & 0.836 \\
\hline Tingkat konsentrasi & 68.40 & 168.604 & 0.411 & 0.475 & 0.843 \\
\hline $\mathrm{PBC}$ & 68.01 & 167.336 & 0.610 & 0.628 & 0.838 \\
\hline $\begin{array}{l}\text { SUBJECTIVE } \\
\text { NORM }\end{array}$ & 68.89 & 165.669 & 0.577 & 0.637 & 0.838 \\
\hline $\begin{array}{l}\text { SUBJECTIVE } \\
\text { NORM }\end{array}$ & 69.56 & 164.577 & 0.532 & 0.561 & 0.839 \\
\hline Cuaca & 69.50 & 163.114 & 0.599 & 0.634 & 0.836 \\
\hline Cuaca & 69.81 & 164.344 & 0.541 & 0.589 & 0.838 \\
\hline PBC & 68.28 & 166.032 & 0.524 & 0.547 & 0.839 \\
\hline T. KETAATAN & 69.03 & 156.887 & 0.685 & 0.686 & 0.831 \\
\hline T. KETAATAN & 69.46 & 162.923 & 0.594 & 0.505 & 0.836 \\
\hline ATTITUDE & 67.82 & 174.597 & 0.353 & 0.436 & 0.846 \\
\hline Ego sentris & 67.52 & 182.028 & 0.069 & 0.482 & 0.853 \\
\hline Ego sentris & 67.30 & 182.625 & 0.069 & 0.426 & 0.852 \\
\hline BK23 & 69.07 & 173.633 & 0.241 & 0.255 & 0.851 \\
\hline
\end{tabular}

Tabel 3. r Table

\begin{tabular}{rrrrr}
\hline $\mathbf{n}$ & df & $\mathbf{a}$ & t table & r table \\
\hline 117 & 115 & 0,05 & 1,981 & 0,18163 \\
& & & & 9
\end{tabular}


Kuesioner dinyatakan valid apabila nilai $\mathrm{r}$ hitung (nilai Corrected Item-Total Correlation) lebih besar daripada $r$ tabel. Pada tabel 4.8 dapat terlihat bahwa variabel PBC, Kondisi Ruas Jalan, dan Subjective norm memiliki nilai Corrected Item-Total Correlation; $\mathrm{PBC}=-0.205$, Kondisi Ruas Jalan $=0.071$, dan Subjective norm $=0,032$ dimana nilai tersebut lebih kecil dari $\mathrm{R}$ Tabel yang bernilai 0.181 . Nilai tersebut menunjukkan bahwa variabel diatas dinyatakan tidak valid, dan tidak perlu dimasukkan untuk uji reliabilitas.

Tabel 4. Tabel Uji Reliabilitas

\begin{tabular}{lcr}
\hline & Reliability Statistics & \\
\hline Cronbach's Alpha & $\begin{array}{c}\text { Cronbach's Alpha Based on } \\
\text { Standardized Items }\end{array}$ & N of Items \\
\hline .883 & .877 & 20 \\
\hline
\end{tabular}

Nilai Cronbach's Alpha Based on Standardized Items merupakan nilai reliabilitas tes secara keseluruhan, semakin besar nilainya maka akan semakin reliabel. Untuk menilai apakah nilai-nilai valid dan reliabel, bandingkan dengan $\mathrm{R}$ Tabel $=0.181$.

Jika nilai Cronbach's Alpha lebih besar dari $r$ Table maka item-item yang digunakan Reliabel atau konsisten, sebaliknya jika nilai Alpha lebih kecil dari $r$ Table maka itemitem yang digunakan tidak reliabel atau tidak konsisten. Pada tabel diatas menunjukan bahwa nilai Cronbach's Alpha yang didapatkan adalah 0,883. Karena nilai Alpha lebih besar dari pada nilai $r$ Table maka dapat disimpulkan bahwa reliabel.

Analisa CATPCA terdiri dari model summary, Variance Accounted For, Component Loadings. Reliabilitas pada sebuah penelitian diambil dari nilai cronbach's alpha dan nilai eigen value. Dimana nilai croncbach's alpha sebaiknya memiliki nilai lebih dari 0.6. (Eisingerich, 2010) dan nilai eigenvalue sebaiknya memiliki nilai di atas 1 (Sriningsih, 2018).

Tabel 5. Tabel Model Summary

\begin{tabular}{lccr}
\hline \multicolumn{4}{c}{ Model Summary } \\
\hline Dimension & Cronbach's Alpha & \multicolumn{2}{c}{ Variance Accounted For } \\
\hline & $\begin{array}{c}\text { Total } \\
\text { (Eigenvalue) }\end{array}$ & \% of Variance \\
\hline 1 & .919 & 7,392 & 43,480 \\
\hline 2 & .624 & 2,421 & 14,243 \\
\hline Total & $.954 a$ & 9,813 & 57,723 \\
\hline \multicolumn{4}{l}{} \\
\hline
\end{tabular}

Pada tabel 5 tersebut dapat dilihat kedua dimensi memiliki nilai cronbach's alpha diatas 0.6 dan kedua dimensi juga memiliki nilai eigenvalue diatas 1. Percent of Variance tersebut menunjukkan angka dari eigenvalue dibagi dengan jumlah variabel, dari penelitian ini yaitu nilai 9.813 akan dibagi dengan 17 sehingga akan didapatkan nilai $57.723 \%$. 
Tabel 6. Tabel Variance Accounted For

\begin{tabular}{|c|c|c|c|c|c|c|}
\hline \multirow{4}{*}{ Indicator } & \multicolumn{6}{|c|}{ Variance Accounted For } \\
\hline & \multicolumn{3}{|c|}{ Centroid Coordinates } & \multicolumn{3}{|c|}{$\begin{array}{l}\text { Total (Vector } \\
\text { Coordinates) }\end{array}$} \\
\hline & \multicolumn{2}{|c|}{ Dimension } & \multirow{2}{*}{ Mean } & \multicolumn{2}{|c|}{ Dimension } & \multirow{2}{*}{ Total } \\
\hline & 1 & 2 & & 1 & 2 & \\
\hline Attitude & .656 & .072 & .364 & .654 & .050 & .704 \\
\hline Attitude & .527 & .126 & .327 & .524 & .115 & .639 \\
\hline Punishment avo & .271 & .360 & .315 & .248 & .345 & .593 \\
\hline Belief & .500 & .058 & .279 & .499 & .045 & .544 \\
\hline $\mathrm{Pa}$ & .322 & .383 & .352 & .251 & .328 & .580 \\
\hline Belief & .518 & .145 & .332 & .512 & .119 & .631 \\
\hline Tingkat konsentrasi & .470 & .073 & .272 & .468 & .003 & .470 \\
\hline PBC & .473 & .222 & .347 & .453 & .168 & .620 \\
\hline Subjective norm & .597 & .090 & .344 & .590 & .004 & .593 \\
\hline Subjective norm & .460 & .050 & .255 & .459 & .033 & .492 \\
\hline Cuaca & .492 & .054 & .273 & .491 & .048 & .539 \\
\hline Cuaca & .354 & .056 & .205 & .353 & .054 & .407 \\
\hline $\mathrm{Pbc}$ & .485 & .077 & .281 & .483 & .057 & .540 \\
\hline T. Ketaatan & .627 & .057 & .342 & .620 & .032 & .653 \\
\hline T. Ketaatan & .494 & .091 & .292 & .489 & .055 & .545 \\
\hline Ego sentris & .271 & .542 & .406 & .193 & .520 & .713 \\
\hline Ego sentris & .159 & .459 & .309 & .104 & .446 & .550 \\
\hline \multirow[t]{2}{*}{ Active Total } & 7,675 & 2,916 & 5,296 & 7,392 & 2,421 & 9,813 \\
\hline & 45,14 & 17,15 & 31,15 & 43,48 & 14,24 & 57,72 \\
\hline$\%$ of Variance & 7 & 5 & 1 & 0 & 3 & 3 \\
\hline
\end{tabular}

Hasil penelitian pada tabel 6 dapat terlihat semua variabel yang terpilih memiliki mean di atas 0.2. Dengan nilai mean di atas 0,2 maka semua variabel tersebut dinyatakan memberikan kontribusi yang substansial/ memiliki pengaruh yang besar terhadap komponen utama.

Tabel 7. Tabel Component Loadings

\begin{tabular}{lcr}
\hline \multicolumn{3}{c}{ Component Loadings } \\
\hline \multirow{2}{*}{ Indicator } & \multicolumn{2}{c}{ Dimension } \\
\cline { 2 - 3 } & $\mathbf{1}$ & $\mathbf{2}$ \\
\hline Attitude & .809 & -.224 \\
\hline Attitude & .724 & -.339 \\
\hline Punishment avoidance & .498 & .588 \\
\hline Belief & .706 & -.212 \\
\hline $\mathrm{Pa}$ & .501 & .573 \\
\hline
\end{tabular}




\begin{tabular}{lcc}
\hline \multicolumn{3}{c}{ Component Loadings } \\
\hline \multirow{2}{*}{ Indicator } & \multicolumn{2}{c}{ Dimension } \\
\cline { 2 - 3 } & $\mathbf{1}$ & $\mathbf{2}$ \\
\hline Belief & .715 & -.344 \\
\hline Tingkat konsentrasi & .684 & .054 \\
\hline Pbc & .673 & .409 \\
\hline Subjective norm & .768 & -.061 \\
\hline Subjective norm & .677 & -.182 \\
\hline Cuaca & .701 & -.219 \\
\hline Cuaca & .594 & -.233 \\
\hline PBC & .695 & .238 \\
\hline T. Ketaatan & .788 & -.179 \\
\hline T. Ketaatan & .700 & -.235 \\
\hline Ego sentris & .440 & .721 \\
\hline Ego sentris & .323 & .668 \\
\hline
\end{tabular}

Tabel Component Loadings menunjukkan distribusi 17 indikator pada dua dimensi yang terbentuk. Component loadings menunjukkan besar korelasi antara suatu variabel dengan dimensi 1 dan dimensi 2, Selanjutnya dimensi 1 disebut sebagai faktor tingkah laku dan dimensi 2 disebut sebagi faktor moralitas. Proses penentuan variabel mana yang akan masuk ke dimensi yang mana dilakukan dengan melakukan perbandingan besar korelasi variabel pada setiap baris.

Pada Tabel 7 setiap variabel telah membentuk dua dimensi. Nilai pada setiap variabel yang menentukan variabel tersebut termasuk dalam faktor tingkah laku maupun faktor moralitas.

Dari penelitian ini diketahui jika variabel yang memengaruhi pelanggaran menerobos lampu merah ada 9 variabel yaitu PBC (Perceived Behavioral Control), Attitude, norma subjektif, cuaca, punishment avoidance, tingkat ketaatan, belief, tingkat konsentrasi dan ego sentris. Jadi, dimensi yang terbentuk adalah sebagai berikut:

- faktor tingkah laku: variabel Attitude, variabel norma subjektif, variabel belief, variabel cuaca, variabel tingkat ketaatan, variabel belief, dan variabel tingkat konsentrasi.

- faktor moralitas: variabel punishment avoidance, dan variabel ego sentris.

\section{Kesimpulan}

Sebagian responden dari penelitian ini di Surabaya sudah memiliki pemahaman mengenai ETLE, jenis pelanggaran ETLE, dan batas kecepatan jalan perkotaan di Surabaya. Dari hasil penelitian ini ditemukan bahwa jumlah responden yang mengetahui dan memahami tentang ETLE, jenis pelanggaran ETLE, dan batas kecepatan jalan perkotaan di Surabaya masih sedikit lebih banyak dibandingkan dengan jumlah 
responden yang ragu-ragu dan tidak mengetahui maupun memahami hal-hal tersebut. Dari segi gender, umur, pendidikan, dan pekerjaan, paling banyak yang sudah memahami mengenai ETLE, jenis pelanggaran ETLE, dan batas kecepatan jalan perkotaan di Surabaya untuk bagian gender adalah pria, untuk bagian rentang umur 26-40, untuk bagian tingkat pendidikan pascasarjana, dan untuk bagian pekerjaan wiraswasta.

Dari hasil analisis CATPCA terhadap pengelompokan 17 faktor yang memengaruhi pelanggaran aturan batas kecepatan pada ruas jalan perkotaan di Kota Surabaya terbentuk 2 dimensi. Dimensi 1 dinamakan Faktor Tingkah Laku dan Kondisi Lingkungan, terdiri dari variabel attitude, variabel norma subjektif, variabel belief, variabel cuaca, variabel tingkat ketaatan, variabel belief, dan variabel tingkat konsentrasi. Dimensi 2 dinamakan Faktor Moralitas, terdiri dari variabel punishment avoidance, dan variabel ego sentris. 


\section{BIBLIOGRAFI}

Alonso, Fr. (2013). "Speed and Road Accidents: Behaviors, Motives, and Assessment of the Effectiveness of Penalties for Speeding." American Journal of Applied Psychology. Vol. 1, No.3, 58-64. Google Scholar

Badan Pusat Statistik Kota Surabaya. (2019). Kota Surabaya Dalam Angka 2019, Badan Pusat Statistik Kota Surabaya, Indonesia. Google Scholar

Direktorat Utama Pembinaan dan Pengembangan Hukum Pemeriksaan Keuangan Negara. (2013). Peraturan Pemerintah Nomor 79 Tahun 2013 Jaringan Lalu Lintas dan Angkutan Jalan, Badan Pemeriksa Keuangan Republik Indonesia, Indonesia. Google Scholar

Ditlantas Polda Jatim. (2022). "Etle Polda Jawa Timur.” Etle Polda Jawa Timur. Google Scholar

Eisingerich, Rubera. (2010). "Drivers of brand commitment: A cross-national investigation." Journal of International Marketing. Vol. 18, No. 2, 64-79. Google $\underline{\text { Scholar }}$

Kusuma, A., Maulina, D., \& Hutami, A. M. (2019). “Analysis Of Speed And SocialPsychology Factors Of Speeding Behaviour On Drivers In DkI Jakarta." Traffic Accident Research Centre Journal of Indonesia Road Safety. Vol. 2, No.3, 133-148. Google Scholar

Sriningsih, M., Hatidja, D., dan Orang, J. D. (2018). "Penanganan Multikolinearitas dengan Menggunakan Analisis Regresi Komponen Utama pada Kasus Impor Beras di Provinsi Sulawesi Utara.” Jurnal Ilmiah Sains. Vol. 18, No. 1. Google Scholar

Sugiyono. (2017). Metode Penelitian Kuantitatif, Kualitatif, dan R\&D, Alfabeta, Bandung, Indonesia. Google Scholar

Wijayanto, J. (2021). "Setahun Ada 3.755 Orang Tewas Akibat Laka Lantas di Jatim." Radar Surabaya. Google Scholar

First publication right:

Jurnal Syntax Fusion: Jurnal Nasional Indonesia

This article is licensed under:

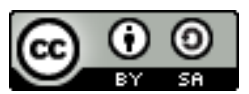

